\title{
Relationships between male giraffes' colour, age and sociability
}

Madelaine P. Castles ${ }^{\mathrm{a}^{*}}$, Rachel Brand, Alecia J. Carter ${ }^{\mathrm{b}}$, Martine Maron ${ }^{\mathrm{c}}$, Kerryn D. Carter ${ }^{\mathrm{a}}$, \& Anne W. Goldizen ${ }^{\mathrm{a}}$.

${ }^{a}$ School of Biological Science, The University of Queensland, Brisbane 4072, QLD, Australia

${ }^{\mathrm{b}}$ ISEM, Université de Montpellier, CNRS, IRD, EPHE, Montpellier, France

${ }^{\mathrm{c}}$ School of Earth and Environmental Sciences \& Centre for Biodiversity and Conservation Science, The University of Queensland, Brisbane 4072, QLD, Australia

*Corresponding author

Correspondence:

E: madelaine.castles@uq.net.au

$\mathrm{Ph}:+61488481721$

P: 59/38 Brougham St, Fairfield, QLD, Australia, 4103

Word count: 10116 (including captions and abstract) 


\section{Relationships between male giraffes' colour, age and sociability}

3 Keywords: colour sexual dimorphism, alternative reproductive tactics, sociability, secondary sexual

4 trait, coat colour, male, giraffe, social patterns

\section{$5 \underline{\text { Abstract }}$}

6 In species in which males signal competitive ability through secondary sexual traits, males with

7 different levels of trait expression may adopt different reproductive tactics to maximise their

8 reproductive success. In fission-fusion social systems, the most dominant males often roam widely in

9 search of females in oestrus, and thus exhibit different patterns of sociability from subordinate males

10 that utilise alternative reproductive tactics. Giraffes, Giraffa camelopardalis, are rare among

11 mammals in that they are sexually dimorphic in colour, and colour is hypothesised to function as a signal of males' social status by displaying their competitive ability. Here we analyse the coat colour and sociability of 77 wild male giraffes over twelve years at Etosha National Park in Namibia to test two premises underlying this hypothesis. First, we demonstrate that not all males darkened at the same rate or to the same degree, and that colour variation increased with age. This suggests that colour is not solely an age-based trait but could be a secondary sexual trait. We then show a distinct

17 difference in the sociability of both young and pale males compared to darker males. Both younger and paler old males tended to be more gregarious while darker males were more solitary. This is consistent with a system where darker, more dominant males roam looking for females in oestrus.

20 Younger or subordinate males may delay roaming or use an alternative tactic, such as remaining in 21 groups with females to gain copulations when a more dominant male is not present. Our results are consistent with the hypothesis that male giraffe coat colour functions as a signal of social status

23 through competitive ability, but deeper study into movement patterns and the costs and benefits associated with darker colours is required. 
In most mammal species without pair bonding or paternal care, the reproductive success of males depends on maximising their mating opportunities (Birkhead \& Parker, 2009). To be successful, a male must find a female, guard her against competitors and be accepted by her as a suitable mate. This creates a scramble competition mating system in which competition between males is likely to be high (Ims, 1988). In such a system, males' access to females is often based upon aggressive interactions with other males that allow males to mutually assess one another's competitive abilities (Berglund, Bisazza, \& Pilastro, 1996). However, aggressive interactions can be risky. Instead, secondary sexual traits can function as honest signals of males' relative competitive ability, allowing males to assess each other visually and thereby reducing the need for aggressive interactions (Santos, Scheck, \& Nakagawa, 2011). Such traits may also signal males' quality to females (Weaver, Koch, \& Hill, 2017).

Secondary sexual traits may take the form of armaments, used in combat and thus related directly to competitive ability, or ornaments, exaggerated traits and/or colours that may be costly to produce or maintain but have no function in physical combat (Berglund et al., 1996). Ornaments have most commonly been studied in species in which male reproductive success is heavily influenced by female mate choice, a phenomenon well known in birds (Berglund et al., 1996). In mammals, armaments such as increased physical size and horns are more common (Caro, 2013; McPherson \& Chenoweth, 2012). However, secondary sexual ornaments do exist in some mammal species, usually in the form of colours. The darkness of male lion manes, Panthera leo, correlates positively with dominance and female mate preference (West \& Packer, 2002) and the colour intensity of sexual skin patches on male mandrills, Mandrillus sphinx, and geladas, Theropithecus gelada, increases with social status

47 (Bergman, Ho, \& Beehner, 2009; Setchell \& Dixson, 2001). In Himalayan tahr, Hemitragus jemhahicus, males with lighter-coloured fringed hairs along their back hold more dominant positions (Lovari, Pellizzi, Boesi, \& Fusani, 2009). (reviewed by Biernaskie, Grafen \& Perry, 2014; Fraser, 2012; Számadó, 2011; Weaver et al. 2017). 
52 The costly signalling hypothesis suggests that only high-quality individuals can present such signals

53 because of the costs they involve, such as the costs of producing or maintaining the signal, including

54 possible costs from aggression from competitors. The index hypothesis does not involve costs, but

55

56

57 instead proposes that physiological/developmental mechanisms mean that only high-quality individuals can produce the signal. In either case, where colour has evolved as an honest indicator of male quality or status, for male-male competition or female preference, it must be related to an underlying aspect of a male's current physical condition, genetic quality or potential reproductive success. Brown and black colours in mammals are thought to almost always be due to eumelanin pigments (Ducrest, Keller \& Roulin, 2008). Extensive research, mostly on birds and insects, has shown that melanin-based colouration is partly heritable and that other traits, such as aggressiveness, immune functioning and sexual activity levels can vary with colour due to pleiotropic effects (reviewed by Ducrest et al., 2008; Roulin 2016).

Males of differing competitive ability may adopt alternative reproductive tactics to maximise their lifetime reproductive success. The tactics used will depend on social and ecological environments and on the relative ability of competitors (Oliveira, Taborsky, \& Brockmann, 2008). Therefore, the tactics that an individual exhibits may change throughout its life depending on its age, current competitive ability and experience, which may affect its dominance status and can also be influenced by environmental conditions (Oliveira et al., 2008). A dominant male may search out, defend and mate with oestrous females unchallenged. One alternative tactic for less dominant males might be to "sneak" copulations when a dominant male is absent, not vigilant, or unable to defend all the oestrous females present. This tactic is used by northern and southern elephant seals, Mirounga angustirostris and M. leonina (Hoelzel, Le Boeuf, Reiter, \& Campagna, 1999; Le Boeuf, 1974), plains zebras, Equus burchelli, (Rubenstein, 1986) and red deer, Cervus elaphus (Clutton-Brock, Guinness, \& Albon, 1982). In musk oxen, Ovibos maschatus, less dominant males spend more time with females, thus increasing their chances of monopolising access to a female if she comes into oestrus in the absence of a more dominant male (Forchhammer \& Boomsma, 1998). Individuals that are competitively excluded due to their size, physical condition or level of experience may instead 
increase their lifetime reproductive success by delaying competitive breeding to invest in growth and building condition. For example, in African elephants, Loxodonta africana, waterbuck, Kobus ellipsiprymnus, and raccoons, Procyon lotor, bachelor herds exist in which younger, smaller males may learn from more experienced males and practise fighting to improve their competitive ability later in life (Evans \& Harris, 2008; Gehrt, Gergits, \& Fritzell, 2008; Wirtz, 1982).

Males' use of different reproductive tactics based on their current competitive ability should lead to predictable differences in males' patterns of sociability, particularly given that an individual's social environment can be an important determinant of fitness (Blumstein, Williams, Lim, Kroeger, \& Martin, 2018; Cameron, Setsaas, \& Linklater, 2009; Silk et al., 2010). Thus individuals may tailor their association patterns and preferences, and sometimes their group sizes, to their own shifting social and reproductive needs. This may result in individuals having varying patterns of sociability in different contexts (Gero, Bejder, Whitehead, Mann, \& Connor, 2005; Muller, Cantor, Cuthill \& Harris, 2018), at different ages (Wey \& Blumstein, 2010) and when in different physical or reproductive conditions (Goldenberg, De Silva, Rasmussen, Douglas-Hamilton, \& Wittemyer, 2014). If competitive ability is signalled through ornamentation, then differently-ornamented males may have measurably different sociability patterns (Oh \& Badyaev, 2010).

Species with fission-fusion social systems present an opportunity to investigate how ornamentation relates to males' patterns of sociability, and thus perhaps to mating tactics. In species with fissionfusion social dynamics, there are no fixed groups; temporary groups change in size and composition frequently. The flexibility of fission-fusion systems allows group sizes to change so that individuals can best balance exploitation of available resources (Aureli et al., 2008; Rubenstein \& Wrangham, 1986; Smith, Kolowski, Graham, Dawes, \& Holekamp, 2008) and predation risk, both of which can vary both spatially and temporally (Kelley, Morrell, Inskip, Krause, \& Croft, 2011). Individuals can choose to join or leave groups based on their own shifting nutritional, social and reproductive needs

103 (Goldenberg et al., 2014; Patriquin, Leonard, Broders, \& Garroway, 2010). Honest visual signals may

104 be particularly useful in fission-fusion social systems because the flexibility of group compositions 
means that individuals may not associate regularly and may thus need to judge the competitive ability or social status of new associates as they come into contact (Bergman \& Beehner, 2009).

107 Giraffes, Giraffa camelopardalis, exhibit fission-fusion social dynamics (Bercovitch \& Berry, 2013;

108 Shorrocks \& Croft 2009), and are rare among mammals in that they are sexually dimorphic in colour.

109 The coats of giraffes have patches that are individually unique and retain their shape throughout the

110 animal's life, but the colour of the patches varies among individuals and may change during an

111 individual's lifetime (Dagg, 1968). The colour of males' patches varies to a much greater extent than

112 those of females. Males' patches can range from pale brown to completely black, and darkness tends

113 to increase with age, though the relationship between colour and age is not clear and causes of

114 variation in this relationship are still unknown (Berry \& Bercovitch, 2012; Brand, 2007). Giraffe social groups are often widely dispersed, depending on resource availability, and may change in composition as often as hourly (Leuthold, 1979). Females come into oestrus for about four days every

117 two weeks when not pregnant and males travel over large distances in search of females in oestrus

118 (Bercovitch, Bashaw \& Del Castillo, 2006). Mating opportunities are determined through a

119 dominance-based polygynous mating system characterised by intense male-male competition

120 (Bercovitch et al., 2006). Males' coat darkness has been positively linked to success in aggressive interactions and female interest (Brand, 2007). Darker males have also been observed to travel over larger distances (Brand, 2007). Giraffes' coats tend to be paler in habitats more exposed to sunlight, towards the end of the dry season when resources are limited, and postpartum in some females

124 (Brand, 2007). Observations and small-scale studies suggest that patch darkness may function as an honest signal of competitive ability of male giraffes (Brand, 2007; Dagg, 2014). However, the social implications of such melanin-based ornamentation, which is uncommon in mammals, have rarely been examined.

In this study we test two predictions stemming from Brand's (2007) hypothesis that male giraffe colour functions as an honest signal of competitive ability. First, if colour expression is an honest

130 signal of competitive ability, we predict that variation in colour should increase with age, with some males never becoming very dark. Second, if dark colour signals social status through competitive 
ability, darker, more dominant males should use mating tactics that make them more likely to encounter females, such as roaming, more than should paler males. In systems where females are spread throughout the landscape and males do not defend harems, roaming is likely to be the most reproductively successful tactic (Fisher and Lara 1999; Whitehead, 1990; 1994). It is also known that younger male giraffes are frequently found in all-male groups, possibly to reduce their predator risk and/or to gain information about resources (Bercovitch \& Berry, 2014). Thus, we predict that darker males should spend more time alone than lighter-coloured males. To test these predictions, we use

139 five metrics of sociability and twelve years of photographs of 77 male giraffes from a large, wild

140 population in the Etosha National Park in Namibia. Specifically, we aimed to (1) determine the 141 relationship between males' age and colour; and (2) investigate how colour and age relate to the 142 association patterns of males. This study population of giraffes provides a valuable opportunity to 143 understand the behaviour of giraffes in a very natural setting, as it is part of a large population of over 1443,000 giraffes (Kilian, 2015) that occupy the 22,270 $\mathrm{km}^{2}$ national park, which is not fenced internally.

\section{$145 \underline{\text { Methods }}$}

\section{Study population, study site and study periods}

147 Our study subjects were male members of the population of giraffes (G. c. angolensis) that inhabit an approximately $1000 \mathrm{~km}^{2}$ area in the southern-central region of the Etosha National Park, Namibia $\left(19^{\circ} 10^{\prime} \mathrm{S}, 15^{\circ} 54^{\prime} \mathrm{E}\right)$. We collected photographs, demographic and grouping data on the giraffes in this population intensively during four study periods spanning twelve years. These studies occurred during May 2004-January 2006, May 2009-April 2010, July-December 2013 and April-November in 2015 and 2016 (Studies 1-4). Individuals were distinguished by their unique patch patterns, which were recorded in a photographic catalogue, allowing us to repeatedly identify individuals across periods. Over this twelve-year period, we identified 1467 individual giraffes, 646 of which were male. A mean of $451 \pm 60$ (SE) giraffes was identified during each study. Photographs of identified males taken ad libitum outside of these periods were also included in our patch darkness analysis. 
158 We collected data along four road transects of approximately $65 \mathrm{~km}$ each in length. We drove each

159 transect evenly in morning and afternoon sampling periods, varying the direction of travel

160 haphazardly, and did not drive the same transect twice in one day. Data were not collected during the middle of the day (1100-1500) as giraffes rest in the shade during the hottest period and are more difficult to find, identify and observe. A mean of one group flux event (a change in group composition) every three hours has been recorded for this population (Castles, 2018), so this protocol allowed ample opportunity for individuals to change associates between sample periods, increasing the likelihood that association data were independent. When a group of giraffes was encountered along a transect, we recorded the group's location, size and composition. We also recorded the apparent age class of each individual and photographed its left and right sides where possible for identification and patch darkness scoring. Groups were defined as individuals foraging or moving together, as has previously been used to define giraffe groups (Carter, Brand, Carter, Shorrocks, \&

170 Goldizen, 2013). Groups were generally self-defining as there was clear spatial differentiation among 171 groups. In the rare cases when groups were not self-defining, we divided individuals into groups in 172 which the outer individuals were within $400 \mathrm{~m}$ of each other, as was usually the case. All individuals 173 were assumed to be associating equally with all other group members ("gambit of the group",

174 Whitehead \& Dufault, 1999). If an individual was sighted more than once on a transect drive, only the 175 first observation was used. Due to park regulations all observations were made from inside a vehicle, 176 which had to remain on roads. These roads were designed for tourism and thus were not evenly 177 spaced through the habitat, leaving some areas of our giraffes' home ranges unavailable to us. Similar 178 data collection protocols were used in all four studies, ensuring comparability of data (Brand, 2007;

179 Carter, Brand, et al., 2013; Carter, Seddon, Frere, Carter, \& Goldizen, 2013). Data collection was 180 approved by the Namibian Ministry of Environment and Tourism and animal ethics approval was granted by the University of Queensland Native/Exotic Wildlife and Marine Animals Animal Ethics Committee (approval nos. SBS/439/14, SBS/093/11/GCF and SIB/124/09/URG). 
184 At each group sighting during study periods 1, 3 and 4, as well as recording behavioural and 185 demographic data, we also recorded a patch darkness score for each male in the observed groups. 186 Following Brand (2007), scores were based on brown colour saturation or "gross darkness," as 187 opposed to variation in hue, and were assumed to correspond to incrementally increasing levels of eumelanin pigmentation (Meunier, Figueiredo Pinto, Burri, \& Roulin, 2011). Patch darkness was broken into four categories (1-4) based on shades of brown, with half scores representing transitional states between shades (Figure 1). Transitional characteristics included darkening at the centre of

191 patches (Berry \& Bercovitch, 2012) or in particular regions of the body. We developed a graduated colour reference chart with descriptors of each category. A score of 1 represented a giraffe that was washed out with patches that were difficult to distinguish from the paler background, a 2 was equivalent to the colour of a standard female or sub-adult male and 4 represented a male whose patches were almost entirely black.

197 Giraffes were categorised in the field as juvenile, sub-adult or adult based on their height, behaviour and ossicone development. Juveniles, aged between zero and two years, were recognised by their short stature, up to $3.25 \mathrm{~m}$ (Dagg \& Foster, 1982), and behaviours including following female adults, suckling or being in crèche groups with other young individuals. Sub-adults, aged between two and four years, were independent of their mothers but shorter than adults. Male sub-adults also had

202 fringed hair around the tips of their ossicones, which is worn off in adulthood. Individuals over the age of four years were considered sexually mature and thus adults, though it should be noted that males continue to grow until age eight.

205 To determine the accuracy of ages assigned in the field, we reviewed the sightings data and photographs. If an individual was assigned the same age at three or more sightings in a period, we assumed it to be correct. If we found inconsistencies or an individual was sighted fewer than three times during one of the studies, we examined the ages of the individual in the other studies and reviewed photographs. We were able to estimate the age of individuals from their height in 
211 individual, it was recorded as an individual of unknown age in the group and included in the social

212 network but not in further analysis.

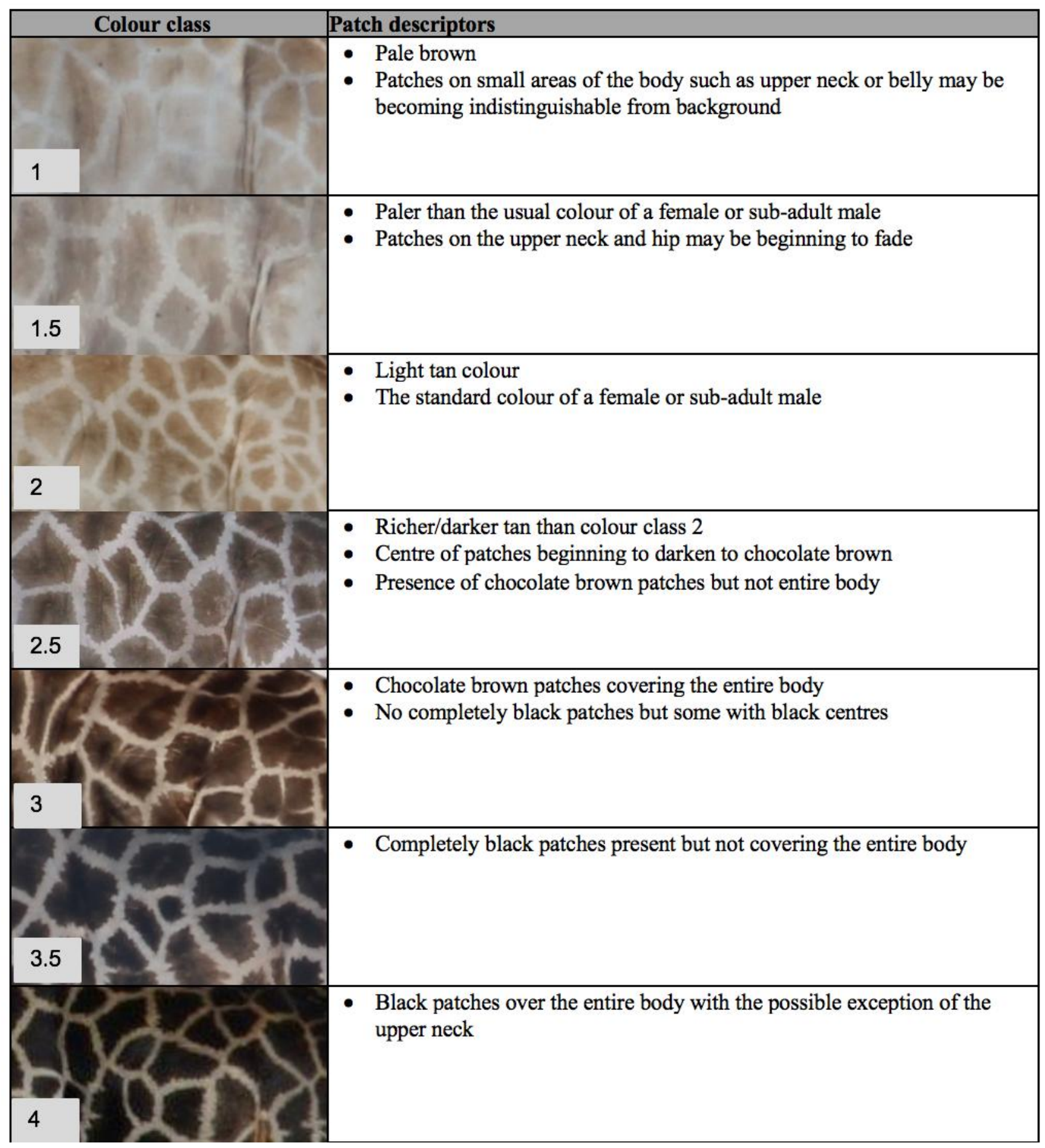

214 Figure 1: Patch darkness colour categories and descriptors for male giraffes in the Etosha National 215 Park 
217 To account for errors in age estimation that may arise from variation in height among individuals of

218 the same age, and because we could not estimate the birth month for most individuals, identified

219 giraffes were further classified into multi-year age cohorts based on their age class when first sighted

220 (Table 1). We could not reliably estimate the age cohort of individuals that were first observed as

221 adults after 2005 as they could have been between four and fifteen years old when first seen, so these

222 individuals were included in the network but not in further analysis (40.1\% of individuals). This led to

223 a skew in the proportions of different age classes recorded in each study, with the oldest age

224 categories only recorded in the later studies. This was accounted for in analyses.

225 Table 1: Giraffe age categories used in this research. Individuals were classed as juveniles (J), sub-

226 adults (S), young adults (YA), middle-aged adults (MA), or old adults (OA) based on their age when

227 first sighted. Individuals observed as adults in 2004-2005 could only be aged in 2015-2016 when we

228 knew that they had to be at least fifteen years old. Individuals first observed as adults in all other

229 study-periods were included as "age unknown" in networks and then removed from further analysis.

230

\begin{tabular}{ll}
\hline Age Category & Age at 2016 (years) \\
\hline Juvenile & $<2$ \\
Sub-adult & $2-4$ \\
Young adult & $5-8$ \\
Middle-aged adult & $9-14$ \\
Old adult & $15+$ \\
Adult (age unknown) & $4+$ \\
\hline
\end{tabular}

$231 \quad$ Patch darkness scoring from photographs

232 Patch darkness scores were not recorded in the field for all individuals in all four of the studies and

233 the data in the four periods were collected by different observers. Although all observers were trained

234 to score colour by the previous observers, with photographs as references, we could not completely

235 ensure the reliability of male colour scores given in the field. Instead, we chose to score male patch

236 darkness from photographs. We included 249 photographs taken opportunistically by R. Brand and

237 other visiting researchers outside of the times of the four studies (see acknowledgements), which

238 increased the size and improved the continuity of the dataset. Photographs of identified males from

239 over the 12 years of data collection were collated into the following five periods: 2004-2005 (P1), 
241 age analysis (Aim 1) to aged males that had been photographed in a minimum of two periods. This

242 provided a candidate set of 77 males (mean of $3.0 \pm 1.0 \mathrm{SD}$ periods/individual). We only calculated

243 sociability metrics for individuals that had been seen a minimum of 8 times in a period (see below),

244 thus analyses for Aim 2 were limited to a subset of 44 males $(\mathrm{N}=44$, mean $=1.1 \pm 0.7$

245 periods/individual). As no group composition data were collected in P3, because this period was not 246 part of one of our four intensive studies, this period was excluded from the analyses for our second 247 aim.

248 Field conditions meant that it was impossible to standardise lighting conditions or to include a colour 249 standard in photographs. In addition, variation in cameras and image quality over the 12 years of data 250 collection meant that the use of image analysis software (as in Gerald, Bernstein, Hinkson, \& 251 Fosbury, 2001) was not possible. Therefore, we scored patch darkness by eye. Scoring colour consistently has been shown to be possible using photographs (Mizokami, Ikeda, \& Shinoda, 2004; Phuangsuwan, Ikeda, \& Shinoda, 2014). To improve the accuracy of our scoring we only scored images taken under daylight lighting (no dawn or dusk photographs), and which were not backlit, hazy or blurry.

For each photograph we scored patch darkness using the same colour categories and criteria as in the field. When more than one image was taken at a sighting, we first scored each photograph blindly, then compared all images and scores against each other and the scoring criteria to decide upon the score for that sighting (mean $1.8 \pm 1.2$ images/sighting). When a giraffe was photographed at more than one sighting in a period, we again blindly scored the photographs then compared all images and scores to each other and the scoring criteria and decided on the score for the period (median 3, IQR 16 sightings/period). Using multiple photographs in this way likely increased our accuracy. In the rare cases in which a male appeared to change colour class during a period, we assigned it the lowest recorded category for that period. If an image did not meet the acceptable photograph conditions it was not scored, and if we had no acceptable images in a period for a given individual, that period was 
removed for that individual from the analysis. All image scoring was conducted by the same observer

267 (MC), under standardised lighting using a MacBook Pro with the screen turned to full brightness. We 268 chose not to crop out the background of photographs as the human brain uses cues from the

269 surrounding environment to adjust colour perception (Mizokami et al., 2004).

\section{$270 \quad$ Validation of photo colour scoring}

271 While field scores were not used for analysis, to test that we could score photographs as accurately as 272 in the field we took a random subset of 200 sightings of males from P5 in which males had been 273 assigned a colour score in the field and a photograph had been taken. We used only sightings where

274 the photograph was taken in acceptable light conditions and the animal was not obstructed by 275 vegetation or out of focus. Multiple sightings of the same individual were allowed. The colour of the male in each photograph was then scored independently by three trained observers using the same criteria as used in the field. Observer one (M Castles) completed two full, seven-month data collection

278 periods (2015 and 2016), while observers two and three had each spent one month in Etosha National

279 Park collecting field data on this project as research assistants in 2016. The accuracy test was

280 conducted in mid-2017, reducing the likelihood of observers being able to recognise individuals and 281 recall the scores given to them in the field.

282 To test inter-observer reliability among the three observers, we calculated an intra-class correlation 283 coefficient (ICC) and 95\% confidence intervals in the R package psych (Revelle, 2017), based on the 284 mean of four scores, those of the three observers and the field score, absolute agreement (exact same 285 score given), and a two-way mixed effects model (Koo \& Li, 2016). We then tested the correlation 286 between the photograph scores of MC and the field scores using a Spearman's rank correlation.

\section{Calculation of association data}

288 We generated weighted social networks for each of the four studies from the observed group 289 compositions using the R package asnipe (Farine, 2017). We excluded groups for which less than $29080 \%$ of individuals could be identified (Silk, Jackson, Croft, Colhoun, \& Bearhop, 2015). To control 291 for differences in grouping patterns between wet and dry seasons (Brand, 2007), we only included 
groups observed between April and November in each study, leaving 2428 groups over the four

293 studies. We calculated the strengths of association (edge weighing) between dyads (pairs of

294 individuals) using the half-weight index (HWI, Whitehead, 2008):

$$
H W I=\frac{X}{X+Y_{a b}+\frac{1}{2}\left(Y_{a}+Y_{b}\right)}
$$

295

296

297

298

299

300

301

302

303

304

305

306

307

308

309

310

311

312

313

in which $X$ is the number of times individuals $a$ and $b$ were seen together, $Y_{a b}$ denotes the number of times both individuals were observed in a survey but not together and $Y_{a}$ and $Y_{b}$ denote times that $a$ was observed but not $b$ and vice versa. This index controls for biases that may arise when individuals are more likely to be seen apart than together, which is likely to occur when individuals have large home ranges and the population exhibits a high degree of fission-fusion dynamics (Croft, James, \& Krause, 2008). HWI scores fall between zero and one, with zero representing a dyad that is never observed together and one a dyad that is always in the same group (Cairns \& Schwager, 1987;

Whitehead, 2008). We did not filter rare edges or individuals (nodes) with low sighting frequencies. We could not analyse the social network metrics of individuals with low sightings (see below), however these individuals may be important to the structure of the network and the position of others within it (Croft et al., 2008) and thus were included in the calculations of other individuals' metrics.

\section{Calculation of gregariousness and sociability metrics}

To quantify males' social behaviour, we calculated two metrics of gregariousness, two social network metrics that describe different aspects of individuals' sociability, and the proportion of individuals' associates (group members) that were males. These metrics were calculated for data collected during each of the four studies.

Gregariousness metrics:

Median group size: We calculated the median group size for each male in each study. To standardise across the studies, we calculated the median group size for all males in each study 
and subtracted this from each male's median to obtain a difference from the study's median

315 group size.

316 Proportion of time spent alone: We divided the number of sightings where an individual was

317 alone by its total number of sightings. Again, to standardise we calculated the median time spent

318 alone across all males in each study and subtracted this from males' scores to obtain differences

319 from the median proportion of time alone.

Sociability metrics:

321

Weighted transitivity: Also known as clustering coefficient, this metric measures the degree to which an individual's associates are also connected to one another. Individuals in highly “cliquish" or tight-knit subgroups have high relative transitivity (see Whitehead, 2008 Table 5.3 for formula). We predicted that darker males would have lower transitivity than other males. Darker, more dominant males are expected to spend more time roaming in order to encounter and assess females, and thus would spend less time with particular males and have lower transitivity. Younger, subordinate male giraffes are often seen in all-male groups (Bercovitch \& Berry, 2014), and thus would be expected to have higher transitivity.

Weighted Betweenness: This metric determines how important an individual is as a connector between others in the network by measuring the number of dyads whose geodesic distance (shortest path) passes through the individual (see Whitehead, 2008 page 173 for a description of the calculation). High betweenness scores represent individuals that are important network connectors and thus may be key in the spread of information through a network. We predicted that darker males would have higher betweenness measures as they would encounter, and thus associate with, more individuals than would other males. (minus one to account for the individual) and the number of other males in the group. We then summed each of these for each male and divided their total number of male associates by their 

males in each study and subtracted this from the score for each male in that study.

341 Comparison of raw individual metrics from networks that are of different sizes and have different

342 characteristics is not appropriate (Krause, Croft, \& James, 2007). Thus, to allow comparison among

343 transitivity and among betweenness scores across the four studies, we used a similar approach to that

344 of Wilson, Krause, Dingemanse, \& Krause (2013) and ranked each individual within each study by its

345 metric, then rescaled them to fall between zero and one with one representing the highest ranked

346 individual. To reduce inaccuracy due to sparse data we analysed only males seen more than eight

347 times in a particular study. This threshold was chosen as a trade-off between maximising the number

348 of individuals included in the analyses while still suitably sampling their association patterns. We

349 controlled for differences in sighting frequencies among individuals above the minimum number of sightings by utilising a permutation method that maintains group composition and individual sighting

351 frequency while randomly moving individuals among groups (explained below).

\section{The relationship between colour and age (Aim 1)}

353 To test the relationship between males' age and coat colour we ran a cumulative link mixed model in the R package Ordinal (Christensen, 2015). We used colour as an ordered response variable, with age (also ordered) and period as predictors. We also included ID as a random factor. To test the goodness of fit of the model we calculated McFadden's pseudo $\mathrm{R}^{2}$ (Domencich \& McFadden, 1975). This returns a value between zero and one, but values close to one are unlikely and values between 0.2 and 0.4 are considered to represent a suitable model fit (McFadden, 1978). Our model fit value was 0.3.

Homogeneity of variance is not of concern when modelling ordinal data. However, we were interested in differences in the variation in colour among age categories and found clear evidence of increasing variance with age in a preliminary analysis. Therefore, we tested for this formally by treating colour

362 as a numeric variable and running a Levene's Test against age, using the car package in R (Fox \&

363 Weisberg, 2011). This test assesses whether the variance of a variable is statistically different among groups. 
366 To test whether and how individuals' median group size related to colour, we ran a linear mixed

367 effects model with individuals' differences from the study's median group size as the response, colour

368 (ordered) as a predictor and ID and study number as random effects in the R package lme4 (Bates,

369 Bolker, \& Walker, 2015). Because age is related to males' gregariousness (Castles, 2018), we

370 controlled for age by also including it as a predictor in the model. Although there is a relationship

371 between age and colour (see Results below), a chi-square test between ordinal variables showed that

372 the correlation was significant but not strong $\left(R=0.62, X^{2}=35.68\right.$, simulated-P $\left.=0.008\right)$, so both

373 variables could be included in the model (Dormann et al., 2013). We used the same approach to test

374 the relationships between male colour and (a) difference to median proportion of time alone, and (b)

375 difference to median proportion of male associates. Each variable was modelled with age and colour

376 as ordinal predictors and individual identity and study number as random effects. We combined

377 colour classes 3.5 and 4 in all analyses due to low sample sizes of each class. $\mathrm{N}=5$ was our minimum

378 sample size; this was recorded from colour classes 1.5, 2.5, 3 and 3.5+, colour class 2 had 24

379 individuals. To test the fit of each model we compared the log-likelihood of the model with that of a

380 null model, which showed that the included variables significantly improved the predictive

381 performance of all models ( $\mathrm{P}_{\text {group size }}<0.01, \mathrm{P}_{\text {time alone }}=0.04, \mathrm{P}_{\text {male associates }}<0.01$, full results in

382 supplementary material). The sample size did not allow us to include an interaction term between age

383 and colour in any of our five models of the sociability metrics.

384 To examine the relationships between colour, age and each of the social network metrics

385 (betweenness and transitivity), we ran generalised linear mixed effects models with a beta distribution

386 and logit link in the R package glmmTMB (Magnusson et al., 2017). The rescaled- ranked sociability

387 metric was the response variable. As with the gregariousness metrics, because age is related to

388 sociability (Castles, 2018), age was included in the models as a predictor variable along with colour.

389 We included individual identity as a random factor in all models, but study number was not included

390 as it had only minimal influence on the variance of the rescaled ranked data. Network data are non-

391 independent and thus violate this assumption of regression modelling (Croft, Madden, Franks, \& 
James, 2011). Thus, to calculate appropriate p-values we used a randomisation approach by permuting

393 the network, recalculating the sociability metrics and rerunning the model 1000 times (Farine \&

394 Whitehead, 2015). Explanatory variables were considered significant if the observed effect size was

395 larger (further from zero) than $95 \%$ of the randomised effect sizes. This approach has the additional

396 benefit of controlling for differences in sighting frequencies among individuals. Again, we used a log-

397 likelihood comparison with a null model to confirm the model fit. Despite similarity between the

398 models the variables significantly improved our betweenness model when compared to a null model

$399(\mathrm{P}<0.01)$ but not our transitivity model $(\mathrm{P}=0.33$, full results in supplementary material $)$.

\section{$400 \quad \underline{\text { Results }}$}

401 After the removal of unacceptable photographs, we used 1793 photographs to score the patch darkness of 66 males in 206 male/period combinations for Aim 1 and 41 individuals in 44 male/study combinations for Aim 2. This included males in all age classes from juveniles $(<2$ years $)$ to old adults

404 (15+ years). Individuals ranged in patch darkness from 1.5 (paler than an average female) to 4 (almost 405 all patches completely black), with a median darkness score of 2.

\section{Consistency of colour scoring}

407 We calculated an $\mathrm{ICC}_{3, k}$ value of 0.94 with a $95 \%$ confidence interval of $0.93-0.95$, suggesting high inter-observer reliability in scoring colour from photographs (Koo \& Li, 2016). The correlation

409 between the photograph scores of the primary observer (MC) and the scores assigned in the field was 410 significant $(\mathrm{R}=0.84, \mathrm{~N}=200, \mathrm{t}=21.595, \mathrm{D} . \mathrm{F} .=199, \mathrm{P}<0.001)$. We concluded that we could 411 reliably score male colour from photographs under these conditions.

\section{The relationship between colour and age (Aim 1)}

413 The hypothesis that colour functions as a signal of competitive ability predicts that not all males

414 should become equally dark as they age. Our data supported that prediction. In general, coats

415 darkened with age and the oldest males were the darkest; however, variation in colour increased with

416 age (Figure 2). Juveniles were only found to have colour classes 1.5 and 2 while old males ranged

417 from classes 2 to 4 . The Levene's test showed significant differences in the variance of colour scores 
among age classes $(\mathrm{DF}=4, \mathrm{~F}=6.00, \mathrm{P}<0.01)$. Colour class 2 was the most common for all age

419 classes except old males, for which colour 3 was more common. Twenty individuals (26\%) did not

420 change colour between periods at all and one particular individual was recorded as colour 2 as a

421 juvenile, young adult, middle-aged adult and old adult. Colour was linearly and quadratically related

422 to age and period had no significant effect (Table 2).

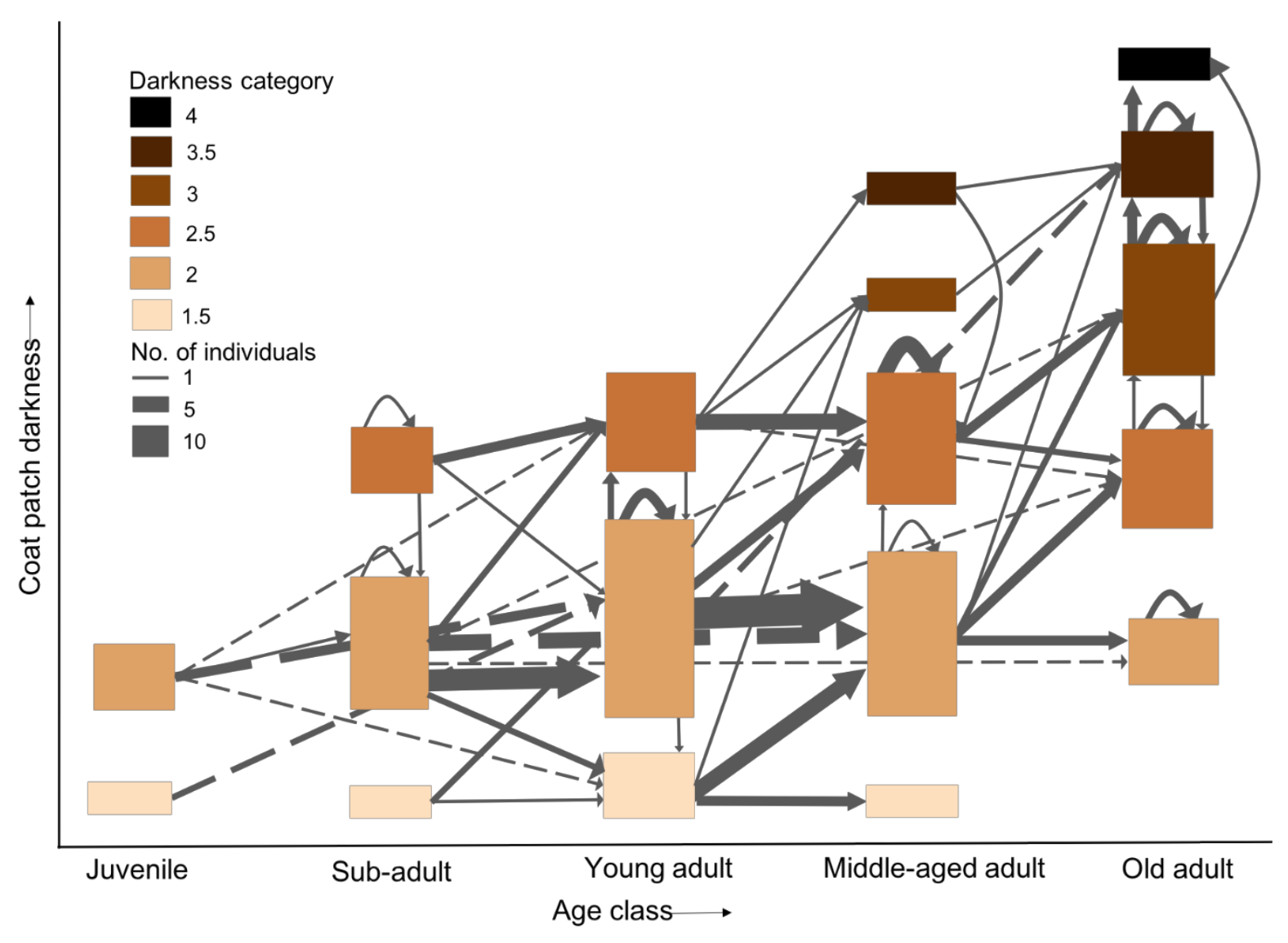

423

424 Figure 2: Progression of colour with age for 66 males, each photographed in a median of 3.0 periods,

425 for a total of 206 male-period combinations. Box height denotes the number of individuals observed

426 in each category and line width denotes the number of individuals that followed a given path between

427 age classes. Dashed lines represent paths that skipped an age class, which occurred when individuals

428 were not sighted in consecutive periods or their colour could not be scored. Vertical lines show cases

429 where individuals were in the same age class in consecutive periods and changed colour, and "U-turn"

430 arrows denote individuals that were in the same age class in consecutive periods but did not change

431 colour. 
433 Table 2: Full model output from the cumulative link mixed-effect model of the effect of age and

434 period on colour (Aim 1). As age was included as an ordered variable the model fits one less

435 polynomial function than there are levels. The model includes 206 observations of 66 males.

436 Significant variables are shown in bold.

437

\begin{tabular}{lllll}
\hline Parameter & Estimate & SE & Z-value & P-value \\
\hline Age - linear & $\mathbf{4 . 4 4}$ & $\mathbf{1 . 0 7}$ & $\mathbf{4 . 1 5}$ & $<\mathbf{0 . 0 1}$ \\
Age - quadratic & $\mathbf{2 . 3 7}$ & $\mathbf{0 . 6 3}$ & $\mathbf{3 . 7 4}$ & $<\mathbf{0 . 0 1}$ \\
Age - cubic & 0.72 & 0.52 & 1.39 & 0.16 \\
Age - quartic & -0.52 & 0.39 & -1.34 & 0.18 \\
Period 2 & 1.39 & 0.86 & 1.61 & 0.11 \\
Period 3 & 2.00 & 1.07 & 1.87 & 0.06 \\
Period 4 & 0.72 & 1.00 & 0.72 & 0.47 \\
Period 5 & 1.46 & 1.11 & 1.32 & 0.19 \\
\hline
\end{tabular}

The relationships between sociability, age and colour (Aim 2)

439 If male giraffes' colour reflects their relative competitive ability, males of different colours might

440 exhibit different mating strategies. Such differences might be reflected in their patterns of sociability.

441 We found partial support for this prediction. Colour class two was the most common $\left(\mathrm{N}_{2}=24 / 44\right.$

442 male/study combinations) but males' gregariousness generally decreased with age and darkness.

443 Gregariousness decreased linearly with age but for colour there was a stark contrast between

444 gregariousness metrics of males that were paler versus those that were darker than colour class 2.5

445 (Figure 3). This result was reflected in significant negative linear relationships between males'

446 differences from the median group size and both colour and age (Table 3) and a quartic relationship

447 between difference to median group size and colour (Table 3). A quartic relationship suggests that

448 there are two points of inflection. We also found that the proportion of time alone (measured as the

449 difference from the study's median) increased linearly with both age and colour, with the effect of

450 colour larger than that of age (Table 3). We found no significant effects of age or colour on rescaled

451 betweenness rank as estimates fell within the spread of possible values from randomised data (Table

452 4). We also found no effect on rescaled transitivity rank, however the variables did not improve the

453 predictive performance of the model compared to a null model (log-likelihood comparison, $\mathrm{P}=0.33$, 
full results in supplementary material). We found no effect of colour or age on the proportion of associates that were males (measured as the difference from the study's median, Table 4).
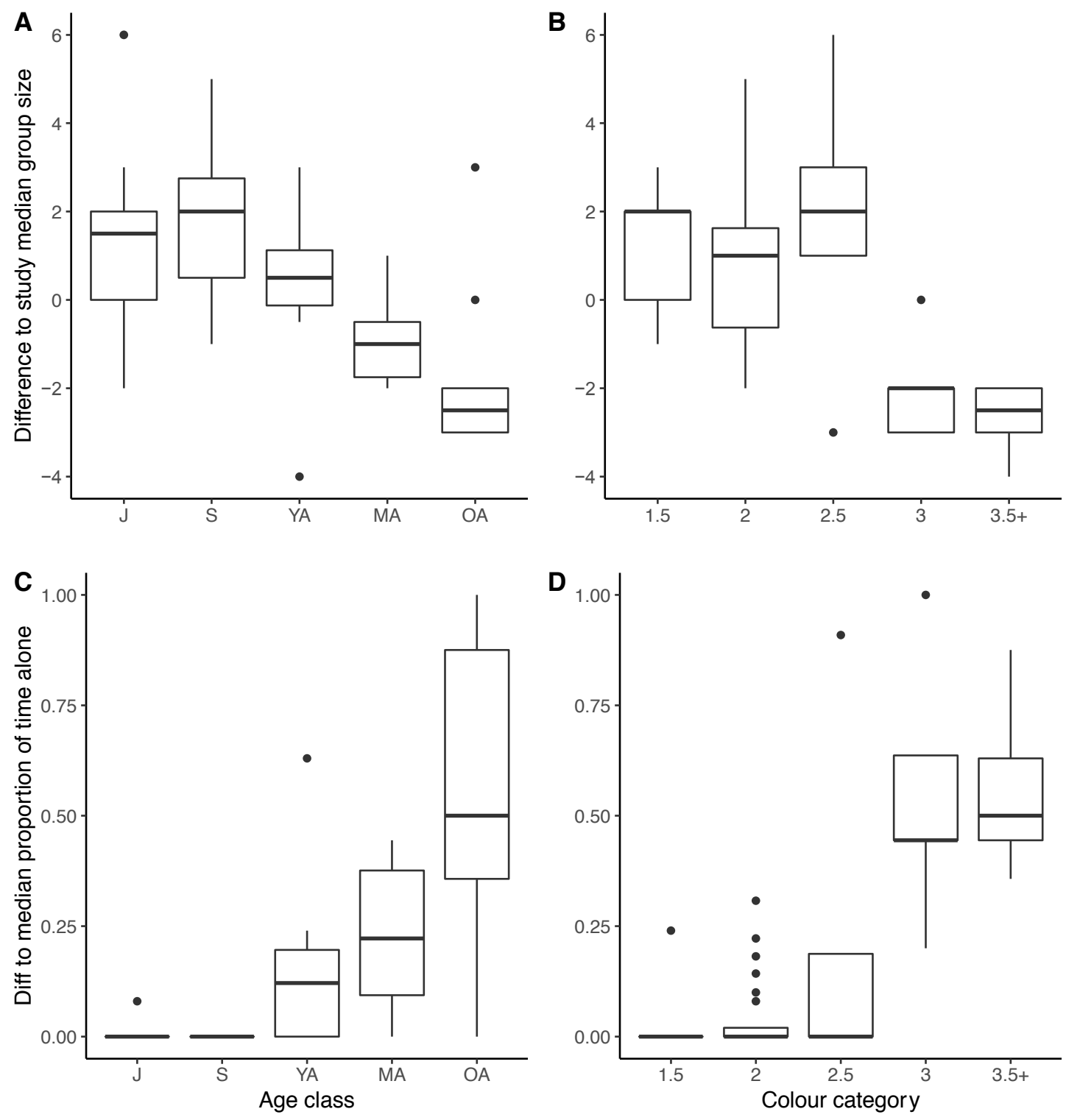

Figure 3: Relationships between males' gregariousness metrics and age and colour $(\mathrm{N}=44$ observations of 41 males in 4 studies). The top row shows the relationships between median group size (measured as the difference from the median for all individuals in a study) and age (A) and colour (B). The bottom row shows the relationships between the difference to study's median proportion of time alone and age (C) and colour (D). Boxes show the median and interquartile range (IQR) with whiskers to 1.5 times the IQR. Data outside of this range are shown as points. 
465 Table 3: Full model output results for the relationship between gregariousness metrics, male

466 associates and colour. As age and colour were included as ordered variables the model fits one less

467 polynomial function than there are levels for each variable. All models were made on 44 observations

468 in the 4 studies. Significant variables are shown in bold.

\begin{tabular}{lllllll}
\hline Measure of sociability & Parameter & Est. & SE & $\boldsymbol{d f}$ & $\mathbf{T}$ & $\mathbf{P}$ \\
\hline Difference to median & (Intercept) & 0.19 & 0.37 & 35.00 & 0.50 & 0.62 \\
group size & Age - linear & $\mathbf{- 2 . 0 8}$ & $\mathbf{0 . 8 4}$ & $\mathbf{3 5 . 0 0}$ & $\mathbf{- 2 . 4 9}$ & $\mathbf{0 . 0 2}$ \\
& Age - quadratic & -0.37 & 0.68 & 35.00 & -0.55 & 0.59 \\
& Age - cubic & 1.22 & 0.65 & 35.00 & 1.87 & 0.07 \\
& Age - quartic & -0.17 & 0.65 & 35.00 & -0.25 & 0.80 \\
& Colour - linear & $\mathbf{- 2 . 1 7}$ & $\mathbf{1 . 0 3}$ & $\mathbf{3 5 . 0 0}$ & $\mathbf{- 2 . 1 1}$ & $\mathbf{0 . 0 4}$ \\
& Colour - quadratic & -1.37 & 0.78 & 35.00 & -1.77 & 0.09 \\
& Colour - cubic & -0.30 & 0.70 & 35.00 & -0.44 & 0.67 \\
Difference to median & Colour - quartic & $\mathbf{1 . 8 2}$ & $\mathbf{0 . 7 1}$ & $\mathbf{3 5 . 0 0}$ & $\mathbf{2 . 5 5}$ & $\mathbf{0 . 0 2}$ \\
proportion of time alone & Age - linear & $\mathbf{0 . 2 2}$ & $\mathbf{0 . 0 9}$ & $\mathbf{3 5 . 0 0}$ & $\mathbf{2 . 5 8}$ & $\mathbf{0 . 0 1}$
\end{tabular}




\begin{tabular}{lllllll} 
& Age - quadratic & 0.05 & 0.07 & 35.00 & 0.67 & 0.51 \\
& Age - cubic & 0.01 & 0.07 & 35.00 & 0.12 & 0.90 \\
& Age - quartic & 0.07 & 0.07 & 35.00 & 0.97 & 0.34 \\
& Colour - linear & $\mathbf{0 . 3 1}$ & $\mathbf{0 . 1 1}$ & $\mathbf{3 5 . 0 0}$ & $\mathbf{2 . 9 5}$ & $\mathbf{0 . 0 1}$ \\
& Colour - quadratic & 0.02 & 0.08 & 35.00 & 0.24 & 0.81 \\
& Colour - cubic & -0.07 & 0.07 & 35.00 & -1.34 & 0.19 \\
& Colour - quartic & -0.06 & 0.07 & 35.00 & -0.86 & 0.39 \\
Difference to median & (Intercept) & 0.01 & 0.04 & 2.37 & 0.25 & 0.83 \\
proportion of male & Age - linear & 0.14 & 0.08 & 12.10 & 1.86 & 0.09 \\
associates & Age - quadratic & 0.00 & 0.06 & 33.32 & 0.05 & 0.96 \\
& Age - cubic & -0.00 & 0.06 & 16.77 & -0.07 & 0.95 \\
& Age - quartic & 0.02 & 0.05 & 32.54 & 0.38 & 0.71 \\
& Colour - linear & -0.05 & 0.09 & 33.44 & -0.52 & 0.61 \\
& Colour - quadratic & -0.00 & 0.07 & 33.41 & -0.04 & 0.97 \\
& Colour - cubic & -0.05 & 0.05 & 33.53 & -0.99 & 0.33 \\
\hline
\end{tabular}

472 Table 4: Full model output results for the relationship between sociability metrics and colour. As age

473 and colour were included as ordered variables the model fits one less polynomial function than there

474 are levels for each variable. All models were made on 44 observations of 41 males in the 4 studies.

\begin{tabular}{llllll}
\hline Measure of sociability & Parameter & Est. & SE & Z & P (Randomisation) \\
\hline Rescaled ranked & (Intercept) & 0.03 & 0.22 & 0.114 & \\
betweenness & Age - linear & -0.07 & 0.49 & -0.14 & 0.97 \\
& Age - quadratic & -0.63 & 0.40 & -1.55 & 0.26 \\
& Age - cubic & -0.61 & 0.37 & -1.62 & 0.19 \\
& Age - quartic & 0.16 & 0.37 & 0.45 & 0.80 \\
& Colour - linear & -0.02 & 0.68 & -0.03 & 0.98 \\
& Colour - quadratic & 0.47 & 0.47 & 0.98 & 0.42 \\
Colour - cubic & 0.20 & 0.38 & 0.52 & 0.41 \\
Rescaled ranked & Colour - quartic & 0.34 & 0.40 & 0.85 & 0.06 \\
& (Intercept) & 0.18 & 0.24 & 0.73 & \\
& Age - linear & 0.29 & 0.54 & 0.55 & 0.50 \\
& Age - quadratic & 0.84 & 0.44 & 1.92 & 0.37 \\
& Age - cubic & 0.38 & 0.40 & 0.96 & 0.76 \\
& Age - quartic & 0.12 & 0.40 & 0.31 & 0.99 \\
& Colour - linear & 0.18 & 0.74 & 0.24 & 0.66 \\
& Colour - quadratic & -0.55 & 0.53 & -1.04 & 0.60 \\
& Colour - cubic & -0.35 & 0.41 & -0.86 & 0.76 \\
& Colour - quartic & -0.14 & 0.42 & -0.35 & 0.72 \\
\hline
\end{tabular}

\section{Discussion}

477 The observed variation in the coat patch darkness of male giraffes is hypothesised to function as an

478 honest visual signal of males' competitive ability or social standing (Brand, 2007; Guindre-Parker \&

479 Love, 2014; Roulin, 2016). We examined the coat colour and sociability of male giraffes over a 12-

480 year period to examine two predictions pertaining to this hypothesis. Our results showed that the rate

481 at which males darken was not equal among males; not all males reached the darkest colour category 
in the oldest age group, and some appeared not to darken with age at all (Aim 1). These results differ

483 from the findings of Berry and Bercovitch (2012), who reported that a small sample size of

484 Thornicroft's giraffe in Zambia all had black spots by approximately nine years of age. Further

485 research is required to understand variation in colour patterns across populations in different environments, but it is known that coat colour of giraffes varies with climate (Brand 2007). We also showed that darker males tended to be in smaller groups and to spend more time alone than paler males, but that males of different colours did not differ in two social network metrics or the proportions of their associates that were male (Aim 2). The first of these results is consistent with the hypothesis that colour may be a secondary sexual trait that honestly signals competitive ability and the second is consistent with the hypothesis that darker males are more likely than paler ones to use a roaming strategy to find oestrous females. We discuss these findings below in the broader context of status signalling and mating tactics before considering potential future avenues to further investigate the function of male patch colour and its relationship to the sociability of male giraffes.

\section{Colour and Age}

As expected for an honest secondary sexual trait, the coat patch darkness of our giraffes generally increased with age but there was considerable variation among individuals. Below a specific threshold in height, weight, or level of experience, males may be competitively excluded from mating opportunities (Fisher \& Lara, 1999), and thus receive minimal benefits from investing in secondary sexual characteristics. Once that threshold is reached and males are competitive, those in good condition may trade off or supplement continued investment in growth with investment in secondary traits (Mysterud, Langvatn, \& Stenseth, 2004). These may be costly (Rohwer \& Ewald, 1981) but can highlight a male's superior physical condition (Roulin, 2016) or convey additional information about testosterone level or genetic quality that may not be conveyed through other physical features (Gasparini et al., 2009; Meunier et al., 2011; Peters, Astheimer, Boland, \& Cockburn, 2000; Setchell, Smith, Wickings, \& Knapp, 2008). Thus, hypothesised condition-dependent signalling of quality and/or status suggests that older males with strong trait expression are likely to be the most dominant (Freeman-Gallant et al., 2010). Giraffes' heights increase towards an asymptote at around eight years 
509 (Dagg \& Foster, 1976) and males live sixteen years on average (Berry \& Bercovitch, 2012); thus, as

510 age increases, height is less likely to be a reliable predictor of age or competitive ability. Brand (2007)

511 concluded that male giraffes' colour is used in competitor assessment and female mate choice, so

512 colour may be more reliable than height for potential competitors and mates to judge competitive

513 ability.

514 The mechanisms that might link colour and quality in giraffes are unknown. However, the following

515 are a number of possibilities that could be explored. (1) Pleiotropic genes could cause a link between

516 colour and testosterone levels, signalling aggression and sexual activity (Ducrest et al., 2008; Setchell

517 et al., 2008; Roulin, 2016). (2) Some studies have shown that melanic pigments are costly to produce,

518 in terms of energy or dietary components required. Since mammalian hair is replaced regularly,

519 changes in body condition (and energy and nutrients available) could cause colour to be linked to

520 body condition (Roulin, 2016). However, we do not know how quickly giraffes replace their hair and

521 thus how rapidly their colour could change. (3) Darker male giraffes could be more likely to be

522 challenged aggressively by other males, so that there could be a cost to a giraffe being dark if he was

523 not as fit and strong as other dark males. Male red junglefowl, Gallus gallus, who had larger combs, a

524 signal of condition and status, and behaved like dominant males, were more likely to be attacked by

525 dominant males than were other males (Parker \& Ligon, 2002). This is an example of the honesty of a

526 signal likely being maintained, at least in part, through punishment of cheaters by conspecifics. While

527 we do not know if a dark but not correspondingly fit giraffe would be "punished", the most intense

528 fights occurred only between pairs of dark males in Brand's (2007) study. (4) Colour may also

529 function through the handicap principle (Zahavi 1975) if darker males suffer higher heat stress

530 (Acharya, Gupta, Sehgal, \& Singh, 1995; West \& Packer, 2002) or are more conspicuous to predators

531 (Stuart-Fox, Moussalli, Marshall, \& Owens, 2003). Further research is required to support the

532 hypothesized link between the colour of male giraffes and their body condition, and these possible

533 mechanisms.

534 Despite this uncertainty about the mechanisms that might link colour and quality in giraffes, our data

535 suggest that giraffes' coat colour functions as a secondary sexual characteristic in the same manner as 
the mane of the African lion. Lions' mane growth and colour increase with age; however, the length

537 of manes can be influenced by injury, testosterone and nutrition (Smuts, Robinson, \& Whyte, 1980;

538 West \& Packer, 2002) and colour can vary with ambient temperature and testosterone level (West \&

539 Packer, 2002). Indeed, there is so much variation in the mane characteristics of male lions that it is not

540 used as a reliable indicator of age (Miller et al., 2016). The colour and length of lions' manes have

541 been associated with female choice and male-male competition, but darker manes have been

542 associated with higher coat surface temperature and higher rates of abnormal sperm (West \& Packer,

543 2002). As well as its use in competitive assessment and mate choice in giraffes, Brand's (2007) results

544 suggest that darker colour may be associated with higher heat stress in environments with high

545 insolation. Some female giraffes become paler towards the end of the dry season and post-partum, and

546 darker males appear to suffer high mortality in drought years (Brand, 2007; A. Goldizen, personal

547 observations; S. Kotting, personal comm.). It thus appears that giraffes' colour may function in a

548 similar way to the lion's mane. This possible thermoregulatory cost of darker coat colours in giraffe

549 requires further research, but if supported it would suggest that a comparable colour handicap system

550 has evolved as an honest signal of male quality in unrelated species in response to similar

551 environmental conditions. Purely visual secondary sexual traits are rare in wild ungulates. However,

552 the sable antelope, Hippotragus niger and the nyala, Tragelaphus angasii both display sexual

553 dimorphism in coat colour (Kingdon \& Hoffmann, 2013) and inhabit regions that may have high

554 insolarity, so colour could function as a sexually selected signalling trait in a similar manner in those

555 species. Further study into the costs associated with coat colour, in particular coat surface

556 temperature, as well as potential links to testosterone or cortisol levels, dominance and reproductive

557 output would increase our understanding of the function of colour in giraffes and other species in hot

558 environments.

559 Linking colour and age to social patterns

560 The sociability patterns of giraffes were consistent with the prediction that males with different levels

561 of trait expression should exhibit different patterns of sociability, as expected if they pursue different

562 breeding tactics. Males using different breeding tactics should exhibit different patterns of sociability 
563 (Oh \& Badyaev, 2010). Indeed, we found that darker and older males tended to be in smaller groups

564 and to spend more time alone than younger and paler males. Gregariousness declined evenly with age

565 but there was a clear distinction between the gregariousness of males above and below colour class

566 2.5. In taxa in which competition exists and quality varies among males, the association patterns of

567 males are driven primarily by the use of tactics that increase mating opportunities through the gaining

568 of access to females in oestrus (Gross, 1996). Thus, the differences in association patterns of male

569 giraffes of different colours are consistent with a system in which dominant, darker individuals roam

570 over large areas looking for females in oestrus and subordinate paler individuals either delay

571 competitive breeding or do not invest heavily in competitive breeding but take opportunistic non-

572 competitive breeding opportunities when available (Whitehead, 1994). This is similar to the "rovers"

573 and "stayers" model described in musk oxen by Forchhammer \& Boomsma (1998). Further research

574 with larger sample sizes is needed to better understand the effects on sociability of the complex

575 interaction between age and colour, but we have shown that both variables are important.

576 The roving strategy, also known as roaming, is common in species in which females are spread out

577 unpredictably throughout the environment (e.g. stray cats, Felis catus, Say \& Pontier, 2004; bridled

578 nailtail wallabies, Onychogalea fraenata, Fisher \& Lara, 1999; African elephants, Barnes, 1982; and

579 sperm whales, Physeter microcephalus, Whitehead, 1993) and increases encounter rates with females.

580 Males with larger home ranges have higher fertilization success in male bridled nailtail wallabies

581 (Fisher \& Lara, 1999). Darker giraffes, which we assumed to be in better physical condition due to

582 demonstrated relationships between melanin levels and condition in other species (Roulin 2016), may

583 be able to cover greater distances than lighter males and thus increase their likelihood of finding

584 receptive females. Further research is required to confirm that darker males roam further or travel

585 more than lighter males. The large home ranges of our giraffes, limited roads and regulations against

586 driving off roads in Etosha prevented us from collecting the data required to test this. Darker giraffes

587 are dominant over paler males and are preferred by females (Brand, 2007), so if more than one male

588 attends a receptive female the darkest male will be able to monopolise the opportunity and is more

589 likely to be accepted quickly by the female. This tactic may increase reproductive output, but 
roaming, and establishing and maintaining dominance, are likely to be costly. Travelling great

591 distances requires high metabolic expenditure (Parker, Robbins, \& Hanley, 1984) and limits time

592 available for foraging (Mysterud et al., 2004). Travelling alone also increases predation risk (Alberts

593 \& Altmann, 1995; Lucas, Waser, \& Creel, 1994), particularly if darker individuals are more conspicuous (Stuart-Fox et al., 2003). Dominance interactions can also be energetically costly and males risk injury if interactions escalate to a fight.

A possible alternative explanation for these findings could be that darker males choose to spend most of their time alone or in small groups to avoid aggression from other males, or competition with either sex for food, rather than as a result of roaming in search of receptive females. However, we do not believe that this is the case, at least for most dark males. The reduced sociability of a small number of darker males could be explained by 'retirement', either temporary or permanent, from the mating game, rather than by mating strategies. We saw a small number of apparently very old males that were usually alone and who appeared to be "retired" and not to move very far (M. Castles, unpublished observations). In contrast, most of the darker males seemed to range further than these "retired" males, suggesting that their ranging was due to searching for females, rather than avoiding aggression or competition, which should be possible to achieve in a relatively smaller area. subordinate males delaying competitive breeding to invest in growth and physical condition, which may prove more beneficial over a lifetime. This is the case for young sperm whales, which exclude themselves from mating opportunities by remaining at higher latitudes than breeding females (Best, 1979; Waters \& Whitehead, 1990). Males that form bachelor groups may also gain additional benefits

611 of reduced predation risk and opportunities for social learning. This may be an explanation for the bachelor groups of giraffes observed in this population and others (Bercovitch \& Berry, 2014; Brand,

613 2007). Paler, older males that are not competitive may "make the best of a bad situation" by

614 remaining near females to gain access to them when more dominant males are not around

615 (Koprowski, 1993). "Sneaker" males have proven successful in ring-tailed coati, Nasua nasua, siring 616 between 9 and 23\% of offspring (Hirsch \& Maldonado, 2011). In eastern grey squirrels, Sciurus 
617 carolinensis, "satellite" males gained equal numbers of copulations to dominants by mating when

618 dominant males were fighting or pursuing other females (Koprowski, 1993). This tactic is most

619 commonly recorded in species that have synchronised breeding seasons because dominant males are

620 unable to guard all of the females in oestrus. However, this tactic could also work when dominant

621 males cannot guard females because the males are not present, as in our system. Alternatively,

622 subordinate male giraffes may benefit from being familiar to females when they come into oestrus,

623 being more readily accepted as a mate as a result (East, Burke, Wilhelm, Greig, \& Hofer, 2003).

624 In a highly competitive environment, the optimal behaviour of a male will depend on the behaviour

625 and competitive ability of other males (Gross, 1996; Schradin \& Lindholm, 2011). The point at which

626 a male shifts reproductive tactics should occur when the maximum fitness benefit of the alternative

627 tactic equals the minimum benefit of the dominant tactic (Gross, 1996). Colour class 3 was only

628 achieved by middle-aged and old adults and was more common in old adults. Middle-aged adults (8-

62915 years), should have reached or be close to their peak height (Dagg, 2014) and thus be physically

630 competitive. We suggest that middle-aged males in good condition may be able to increase their

631 reproductive success by investing in colour to signal their competitive status and thus improve their

632 chances of efficiently out-competing other males through visual assessment and more easily gain

633 access to mates. If so, once they reach colour class 3, males may gain increased fitness benefits from

634 switching to roaming behaviour in this population.

635 Despite the clear trends in patterns of gregariousness, we found no effect of age or colour on social

636 network metrics. Carter, Brand et al. (2013) calculated social network metrics for non-juvenile males

637 in this population in 2004-2005 and 2009-2010 based on a minimum of six sightings of each

638 individual. They found that males' metrics were no different to those expected from random

639 assortment and suggested that because males move between groups regularly their association

640 patterns may be essentially random. This may also be an explanation for our finding. However, as

641 younger and paler males are more gregarious, we may have expected to see some structure to their

642 association patterns. The roaming behaviour of adult males makes them notoriously difficult to

643 sample and while we increased our minimum number of sightings of individuals to eight for inclusion 
644 in our analyses, we still may not have had enough statistical power to distinguish an overall pattern.

645 Indeed, our model to test for a relationship between age, colour and transitivity did not explain the

646 variation better than a null model.

647 We found no effect of age or colour on the proportion of a male's associates that were male. Thus,

648 while males' overall number of associates decreased with increasing darkness, males of all levels of

649 darkness associated with similar ratios of males to females. This is surprising as males that roam

650 should prefer to associate with females when they are associating, thus have a lower proportion of

651 male associates. A possible explanation for this is the apparent importance of aggregations around

652 resources such as vegetation patches and waterholes, which seem to strongly drive grouping patterns

653 in this population (Castles, 2018). Where resources are limited, males may have to associate with both

654 females and males regardless of the potential for competitive or aggressive interactions. Furthermore,

655 we did not include the colour of male associates in our analysis. If we had, we may have found darker

656 males were less likely to tolerate the presence of similarly-coloured competitors. It may be unusual to

657 find two very dark males in a group, but paler males may be tolerated by dark ones (Brand, 2007).

658 This is an avenue for future analysis.

659 While our results do not directly relate giraffe colour to males' social status or roaming patterns, they

660 support the following two predictions of this hypothesis: (1) if colour is linked to competitive ability,

661 then not all males should increase equally in colour expression with age, and (2) males with different

662 degrees of trait expression exhibit different patterns of sociability, as would be expected if they pursue

663 different mating tactics. Using longitudinal data, we show that not all males reach the peak trait

664 expression by old age and that darker males are more likely to be found alone or in small groups. Our association data show that fission-fusion dynamics allow males to tailor their association patterns depending on their age and colour. These patterns likely reflect variation in reproductive tactics, but

667 further research, including movement data, is required. In this study we focused on colour, but male

668 giraffes also continue to invest in bulk and skull ossification as they age (Simmons \& Scheepers,

669 1996). These features are likely to be advantageous in the "necking" fighting technique used by

670 giraffes but may also be used in visual competitive assessment (Kraaijeveld, Kraaijeveld-Smit, \& 
671 Komdeur, 2007). It is common for individuals to display multiple features as complementary signs of

672 their fitness (Vergara \& Fargallo, 2011); thus, future studies on the dominance, signalling of

673 competitive ability and life history traits of giraffes should include these features. Environmental

674 conditions may also be important factors influencing colour but we could not reliably test for this

675 because we did not have an even spread of ages and colours in each period. Further research,

676 comparing courtship and mating behaviour among males, is needed to determine the evolutionary

677 fitness benefits that males of different colour gain from using different reproductive tactics in

678 societies with fission-fusion dynamics. 
679

680

681

682

683

684

685

686

687

688

689

690

691

692

693

694

695

696

697

698

699

700

701

702

703

704

705

\section{$\underline{\text { References }}$}

Acharya, R. M., Gupta, U. D., Sehgal, J. P., \& Singh, M. (1995). Coat characteristics of goats in relation to heat tolerance in the hot tropics. Small Ruminant Research, 18(3), 245-248.

Alberts, S. C., \& Altmann, J. (1995). Balancing costs and opportunities: dispersal in male baboons. The American Naturalist, 145(2), 279-306.

Aureli, F., Schaffner, C. M., Boesch, C., Bearder, S. K., Call, J., Chapman, Connor, R. C., Di Fiore, A., Dunbar, R. I., Henzi P., Holekamp, K., Kortstjens, A. H., Layton, R., Lee, P., Lee, P. Lehmann, J., Manson, J. H., Ramos-Fernandez, G. Strier, K. B., \&Van Schaik, C. P. (2008). Fission-fusion dynamics new research frameworks. Current Anthropology, 49(4), 627-654.

Barnes, R. (1982). Mate searching behaviour of elephant bulls in a semi-arid environment. Animal Behaviour, 30(4), 1217-1223.

Bates, D., Bolker, B., \& Walker, S. (2015). Fitting linear mixed-effects models using lme4. Journal of statistical software, 67(1).

Bercovitch, F. B., Bashaw, M. J., \& del Castillo, S. M. (2006). Sociosexual behavior, male mating tactics, and the reproductive cycle of giraffe Giraffa camelopardalis. Hormones and Behavior, 50(2), 314-321.

Bercovitch, F. B., \& Berry, P. S. M. (2013). Herd composition, kinship and fission-fusion social dynamics among wild giraffe. African Journal of Ecology, 51(2), 206-216.

Bercovitch, F. B., \& Berry, P. S. M. (2014). The composition and function of all-male herds of Thornicroft's giraffe, Giraffa camelopardalis thornicrofti, in Zambia. African Journal of Ecology, 53(2), 167-174.

Berglund, A., Bisazza, A., \& Pilastro, A. (1996). Armaments and ornaments: an evolutionary explanation of traits of dual utility. Biological Journal of the Linnean Society, 58(4), 385-399.

Bergman, T. J., Ho, L., \& Beehner, J. C. (2009). Chest color and social status in male geladas (Theropithecus gelada). International Journal of Primatology, 30(6), 791-806.

Berry, P. S. M., \& Bercovitch, F. B. (2012). Darkening coat colour reveals life history and life expectancy of male Thornicroft's giraffes. Journal of Zoology, 287(3), 157-160. 
Best, P. B. (1979). Social organization in sperm whales, Physeter macrocephalus. In H. E. Winn \& B. L. Olla (Eds.), Behavior of Marine Animals: Current Perspectives in Research (pp. 227-289). Boston: Springer US.

Biernaskie, J. M., Grafen, A., \& Perry, J. C. (2014). The evolution of index signals to avoid the costs of dishonesty. Proceedings of the Royal Society B: Biological Sciences, 20140876.

Birkhead, T. R., \& Parker, G. A. (2009). Sperm competition and mating systems. In J. R. Krebs \& N. B. Davies (Eds.), Behavioural ecology: an evolutionary approach (Vol. 4). Oxford, UK: Blackwell Publishing.

Blumstein, D. T., Williams, D. M., Lim, A. N., Kroeger, S., \& Martin, J. G. A. (2018). Strong social relationships are associated with decreased longevity in a facultatively social mammal. Proceedings of the Royal Society B: Biological Sciences, 285(1871).

Brand, R. (2007). Evolutionary Ecology of Giraffes (Giraffa camelopardalis) in Etosha National Park, Namibia. (PhD), Newcastle University, Newcastle, UK.

Cairns, S. J., \& Schwager, S. J. (1987). A comparison of association indices. Animal Behaviour, 35, 1454-1469.

Cameron, E. Z., Setsaas, T. H., \& Linklater, W. L. (2009). Social bonds between unrelated females increase reproductive success in feral horses. Proceedings of the National Academy of Sciences of the United States of America, 106(33), 13850-13853.

Caro, T. (2013). The colours of extant mammals. Seminars in Cell and Developmental Biology, 24(6-

Carter, K. D., Brand, R., Carter, J. K., Shorrocks, B., \& Goldizen, A. W. (2013). Social networks, long-term associations and age-related sociability of wild giraffes. Animal Behaviour, 86(5), 901-910.

Carter, K. D., Seddon, J. M., Frere, C. H., Carter, J. K., \& Goldizen, A. W. (2013). Fission-fusion dynamics in wild giraffes may be driven by kinship, spatial overlap and individual social preferences. Animal Behaviour, 85(2), 385-394.

Castles, M. (2018). Drivers of sociability and fission-fusion dynamics in a population of wild giraffes (Giraffa camelopardalis). (PhD), University of Queensland, Brisbane, Australia. 
734 Christensen, R. H. B. (2015). Ordinal - regression models for ordinal data. R package Version 2015.628. Retrieved from http://www.cran.r-project.org/package=ordinal/

736 Clutton-Brock, T. H., Guinness, F. E., \& Albon, S. D. (1982). Red deer: behavior and ecology of two 737 sexes. Chicago: University of Chicago press.

Croft, D. P., James, R., \& Krause, J. (2008). Exploring animal social networks. Princeton: Princeton University Press.

Croft, D. P., Madden, J.R., Franks, D. W., \& James, R. (2011). Hypothesis testing in animal social networks. Trends in Ecology \& Evolution, 26(10), 502507.

Dagg, A. I. (1968). External features of giraffe. Mammalia, 32, 657.

Dagg, A. I. (2014). Giraffe: Biology, behaviour and conservation. New York: Cambridge University Press.

Dagg, A. I., \& Foster, J. B. (1976). The giraffe: its biology, behaviour, and ecology. Malabar, Florida: Krieger Publishing Company.

Dagg, A. I., \& Foster, J. B. (1982). The giraffe: Its biology, behaviour, and ecology. New York, NY: Van Nostrand Reinholt.

Domencich, T., \& McFadden, D. (1975). Statistical estimation of choice probability functions in Urban travel demand: a behavioural analysis. Amsterdam: North Holland Publishing Co. B., Lafourcade, B., Leitão, P. J., Münkemüller, T., McClean, C., Osborne, P. E., Reineking, B., Schröder, B., Skidmore, A. K., Zurell, D., Lautenbach, S. (2013). Collinearity: a review of methods to deal with it and a simulation study evaluating their performance. Ecography, $36(1), 27-46$.

Ducrest, A-L., Keller, L., \& Roulin, A. (2008). Pleiotropy in the melanocortin system, coloration and behavioural syndromes. Trends in Ecology and Evolution, 23, 502-510.

East, M. L., Burke, T., Wilhelm, K., Greig, C., \& Hofer, H. (2003). Sexual conflicts in spotted hyenas: male and female mating tactics and their reproductive outcome with respect to age, social status and tenure. Proceedings of the Royal Society of London B: Biological Sciences, 270(1521), 1247-1254. 
Evans, K. E., \& Harris, S. (2008). Adolescence in male African elephants, Loxodonta africana, and the importance of sociality. Animal Behaviour, 76(3), 779-787.

Farine, D. R. (2017). Asnipe: Animal social network inference and permutations for ecologists. $R$ package Version 1.1.3, https://CRAN.R-project.org/package=asnipe.

Farine, D. R., \& Whitehead, H. (2015). Constructing, conducting and interpreting animal social network analysis. The Journal of Animal Ecology, 84(5), 1144-1163.

Fisher, D., \& Lara, M. (1999). Effects of body size and home range on access to mates and paternity in male bridled nailtail wallabies. Animal Behaviour, 58(1), 121-130.

Forchhammer, M. C., \& Boomsma, J. J. (1998). Optimal mating strategies in nonterritorial ungulates: a general model tested on muskoxen. Behavioral Ecology, 9(2), 136-143.

Fox, J., \& Weisberg, S. (2011). An $\{\mathrm{R}\}$ Companion to applied Regression. Retrieved from http://socserv.socsci.mcmaster.ca/jfox/Books/Companion.

Fraser, B. (2012). Costly signalling theories: beyond the handicap principle. Biology and Philosophy, $27,263-278$.

Freeman-Gallant, C. R., Taff, C. C., Morin, D. F., Dunn, P. O., Whittingham, L. A., \& Tsang, S. M. (2010). Sexual selection, multiple male ornaments, and age-and condition-dependent signalling in the common yellowthroat. Evolution, 64(4), 1007-1017. Strength and cost of an induced immune response are associated with a heritable melanin-based colour trait in female tawny owls. Journal of Animal Ecology, 78(3), 608-616.

Gehrt, S. D., Gergits, W. F., \& Fritzell, E. K. (2008). Behavioral and genetic aspects of male social groups in raccoons. Journal of Mammalogy, 89(6), 1473-1480.

Gerald, M. S., Bernstein, J., Hinkson, R., \& Fosbury, R. A. (2001). Formal method for objective assessment of primate color. American Journal of Primatology, 53(2), 79-85. 
Goldenberg, S. Z., De Silva, S., Rasmussen, H. B., Douglas-Hamilton, I., \& Wittemyer, G. (2014). Controlling for behavioural state reveals social dynamics among male African elephants, Loxodonta africana. Animal Behaviour, 95(0), 111-119.

Gross, M. R. (1996). Alternative reproductive strategies and tactics: diversity within sexes. Trends in Ecology \& Evolution, 11(2), 92-98.

Guindre-Parker, S., \& Love, O. P. (2014). Revisiting the condition-dependence of melanin-based plumage. Journal of Avian Biology, 45(1), 29-33.

Hirsch, B. T., \& Maldonado, J. E. (2011). Familiarity breeds progeny: sociality increases reproductive success in adult male ring-tailed coatis (Nasua nasua). Molecular Ecology, 20(2), 409-419.

Hoelzel, A. R., Le Boeuf, B. J., Reiter, J., \& Campagna, C. (1999). Alpha-male paternity in elephant seals. Behavioral Ecology and Sociobiology, 46(5), 298-306.

Ims, R. A. (1988). The potential for sexual selection in males: effect of sex ratio and spatiotemporal distribution of receptive females. Evolutionary Ecology, 2(4), 338-352.

Kelley, J. L., Morrell, L. J., Inskip, C., Krause, J., \& Croft, D. P. (2011). Predation risk shapes social networks in fission-fusion populations. PLoS ONE, 6(8), e24280.

804 Kilian, W. (2015). Aerial Survey of Etosha National Park. Namibia: Etosha Ecological Institute.

Kingdon, J., \& Hoffmann, M. (Eds.). (2013). Mammals of Africa, Volume VI: Hippopotamuses, pigs, deer, giraffe and bovids. London: Bloomsbury Publishing.

Koo, T. K., \& Li, M. Y. (2016). A guideline of selecting and reporting intraclass correlation coefficients for reliability research. Journal of Chiropractic Medicine, 15(2), 155-163.

Koprowski, J. L. (1993). Alternative reproductive tactics in male eastern gray squirrels: "making the best of a bad job". Behavioral Ecology, 4(2), 165-171.

811 Kraaijeveld, K., Kraaijeveld-Smit, F. J., \& Komdeur, J. (2007). The evolution of mutual ornamentation. Animal Behaviour, 74(4), 657-677.

813 Krause, J., Croft, D. P., \& James, R. (2007). Social network theory in the behavioural sciences: potential applications. Behavioral Ecology and Sociobiology, 62, 15-27.

815 Le Boeuf, B. J. (1974). Male-male competition and reproductive success in elephant seals. American Zoologist, 14(1), 163-176. 
817 Leuthold, B. M. (1979). Social organization and behaviour of giraffe in Tsavo East National Park.

818 African Journal of Ecology, 17(1), 19-34.

819 Lovari, S., Pellizzi, B., Boesi, R., \& Fusani, L. (2009). Mating dominance amongst male Himalayan tahr: Blonds do better. Behavioural Processes, 81(1), 20-25.

821

Lucas, J. R., Waser, P. M., \& Creel, S. R. (1994). Death and disappearance: estimating mortality risks associated with philopatry and dispersal. Behavioral Ecology, 5(2), 135-141.

Magnusson, A., Skaug, H. J., Nielsen, A., Berg, C. W., Kristensen, K., Maechler, M., . . Brooks, M. E. (2017). glmmTMB: Generalized linear mixed models using template model builder. $\mathrm{R}$ package Version 0.1.3.

McFadden, D. (1978). Quantitative methods for analyzing travel behaviour of individuals: some recent developments. In D. Hensher \& P. Stopher (Eds.), Behavioural travel modelling. New Haven, USA: Croom Helm.

McPherson, F. J., \& Chenoweth, P. J. (2012). Mammalian sexual dimorphism. Animal Reproduction Science, 131(3), 109-122.

Meunier, J., Figueiredo Pinto, S., Burri, R., \& Roulin, A. (2011). Eumelanin-based coloration and fitness parameters in birds: a meta-analysis. Behavioral Ecology and Sociobiology, 65(4), $559-567$.

Miller, J. R. B., Balme, G., Lindsey, P. A., Loveridge, A. J., Becker, M. S., Begg, C., Brink., H., Dolrenry, S., Hunt., Jansson, I., Macdonald, D. W., Mandisodza-Chikerema, R., Cotterill, A.

Mizokami, Y., Ikeda, M., \& Shinoda, H. (2004). Color constancy in a photograph perceived as a O., Packer, C., Rosengren, D., Stratford, K., Trinkel, M., White, P. A., Winterbach, C.,

Muller, Z., Cantor, M., Cuthill, I. C., \& Harris, S. (2018). Giraffe social preferences are context dependent. Animal Behaviour, 146, 37-49.

843 Mysterud, A., Langvatn, R., \& Stenseth, N. C. (2004). Patterns of reproductive effort in male ungulates. Journal of Zoology, 264(2), 209-215. 
845 Oh, K. P., \& Badyaev, A. V. (2010). Structure of social networks in a passerine bird: Consequences 846 for sexual selection and the evolution of mating strategies. American Naturalist, 176(3), E80-

847

848

849

850

851

852

853

854

855

856

857

858

859

860

861

862

863

864

865

866

867

868

869

870

871

872 E89.

Oliveira, R. F., Taborsky, M., \& Brockmann, H. J. (2008). Alternative reproductive tactics: an integrative approach: Cambridge University Press.

Parker, K. L., Robbins, C. T., \& Hanley, T. A. (1984). Energy expenditures for locomotion by mule deer and elk. The Journal of Wildlife Management, 474-488.

Patriquin, K. J., Leonard, M. L., Broders, H. G., \& Garroway, C. J. (2010). Do social networks of female northern long-eared bats vary with reproductive period and age? Behavioral Ecology and Sociobiology, 64(6), 899-913.

Peters, A., Astheimer, B. L., Boland, J. C. R., \& Cockburn, A. (2000). Testosterone is involved in acquisition and maintenance of sexually selected male plumage in superb fairy-wrens, Malurus cyaneus. Behavioral Ecology and Sociobiology, 47(6), 438-445.

Phuangsuwan, C., Ikeda, M., \& Shinoda, H. (2014). Demonstration of color constancy in photographs by two techniques: Stereoscope and D-up viewer. Optical Review, 21(6), 810-815.

Revelle, W. (2017). psych: Procedures for personality and psychological research. R package version 1.8.3. Northwestern University, Evanston, Illinois.

Rohwer, S., \& Ewald, P. W. (1981). The cost of dominance and advantage of subordination in a badge signalling system. Evolution, 35(3), 441-454.

Roulin, A. (2016). Condition-dependence, pleiotropy and the handicap principle of sexual selection in melanin-based colouration. Biological Reviews, 91(2), 328-348.

Rubenstein, D. I. (1986). Ecology and sociality in horses and zebras. In: Rubenstein D.I., Wrangham R.W. Ecological aspects of social evaluation. Princeton, New Jersey: Princeton University. pp 282-302

Rubenstein, D. I., \& Wrangham, R. W. (1986). Ecological aspects of social evolution. Princeton, New Jersey: Princeton University Press.

Santos, E. S. A., Scheck, D., \& Nakagawa, S. (2011). Dominance and plumage traits: meta-analysis and metaregression analysis. Animal Behaviour, 82, 3-19. 
873 Say, L., \& Pontier, D. (2004). Spacing pattern in a social group of stray cats: effects on male reproductive success. Animal Behaviour, 68(1), 175-180.

875 Schradin, C., \& Lindholm, A. K. (2011). Relative fitness of alterative male reproductive tactics in a mammal varies between years. Journal of Animal Ecology. 80(5), 908-917.

877

878

879

880

881

882

883

884

885

886

887

888

889

890

891

892

893

894

895

896

897

898

899

900 mandrills (Mandrillus sphinx) are associated with gain and loss of alpha status. Hormones and Behavior, 39(3), 177-184.

Setchell, J. M., Smith, T., Wickings, E. J., \& Knapp, L. A. (2008). Social correlates of testosterone and ornamentation in male mandrills. Hormones and Behavior, 54(3), 365-372.

Shorrocks, B., \& Croft, D. P. (2009). Necks and networks: a preliminary study of population structure in the reticulated giraffe (Giraffa camelopardalis reticulata de Winston). African Journal of Ecology, 47(3), 374-381.

Silk, J. B., Beehner, J. C., Bergman, T. J., Crockford, C., Engh, A. L., Moscovice, L. R., Wittig, R. M., Seyfarth, R. M, Cheney, D. L. (2010). Strong and consistent social bonds enhance the longevity of female baboons. Current Biology, 20(15), 1359-1361.

Silk, M. J., Jackson, A. L., Croft, D. P., Colhoun, K., \& Bearhop, S. (2015). The consequences of unidentifiable individuals for the analysis of an animal social network. Animal Behaviour, $104,1-11$.

Smith, J. E., Kolowski, J. M., Graham, K. E., Dawes, S. E., \& Holekamp, K. E. (2008). Social and ecological determinants of fission-fusion dynamics in the spotted hyaena. Animal Behaviour, 76(3), 619-636.

Smuts, G. L., Robinson, G. A., \& Whyte, I. J. (1980). Comparative growth of wild male and female lions (Panthera leo). Journal of Zoology, 190(3), 365-373.

Stuart-Fox, D. M., Moussalli, A., Marshall, N. J., \& Owens, I. P. (2003). Conspicuous males suffer higher predation risk: visual modelling and experimental evidence from lizards. Animal Behaviour, 66(3), 541-550.

Számadó, S. (2011). The costs of honesty and the fallacy of the handicap principle. Animal Behaviour, 81, 3-10. 
901 Vergara, P., \& Fargallo, J. A. (2011). Multiple coloured ornaments in male common kestrels:

902 different mechanisms to convey quality. Naturwissenschaften, 98(4), 289-298.

903 Waters, S., \& Whitehead, H. (1990). Aerial behaviour in sperm whales. Canadian Journal of Zoology,

904 68(10), 2076-2082.

905

Weaver, R. J., Koch, R. E., \& Hill, G. E. (2017). What maintains signal honesty in animal colour

906 displays used in mate choice? Philosophical Transactions of the Royal Society B: Biological

907 Sciences, 372(1724).

908

West, P. M., \& Packer, C. (2002). Sexual selection, temperature, and the lion's mane. Science,

909 297(5585), 1339-1343.

910

Wey, T. W., \& Blumstein, D. T. (2010). Social cohesion in yellow-bellied marmots is established

911 through age and kin structuring. Animal Behaviour, 79(6), 1343-1352.

912

Whitehead, H. (1990). Rules for roving males. Journal of Theoretical Biology, 145(3), 355-368.

913

Whitehead, H. (1993). The behaviour of mature male sperm whales on the Galápagos Islands

914 breeding grounds. Canadian Journal of Zoology, 71(4), 689-699.

915

Whitehead, H. (1994). Delayed competitive breeding in roving males. Journal of Theoretical Biology,

916 166(2), 127-133.

917

Whitehead, H. (2008). Analysing animal societies: quantitative methods for vertebrate social

918 analysis. Chicago: The University of Chicago Press.

919 Whitehead, H., \& Dufault, S. (1999). Techniques for analyzing vertebrate social structure using identified individuals: review and recommendations. Advances in the Study of Animal Behaviour, 28, 33-74.

Wilson, A. D. M., Krause, S., Dingemanse, N. J., \& Krause, J. (2013). Network position: a key 923 component in the characterization of social personality types. Behavioral Ecology and Sociobiology, 67(1), 163-173.

926

Wirtz, P. (1982). Territory holders, satellite males and bachelor males in a high density population of 927 waterbuck (Kobus ellipsiprymnus) and their associations with conspecifics. Zeitschrift für Tierpsychologie, 58(4). 
928 Zahavi, A. (1975). Mate selection-A selection for a handicap. Journal of Theoretical Biology, 53(1), 929 205-214.

930 
932 S1: Log-likelihood tests for model fit Aim 2 models; the relationships between colour and (A) group 933 size, (B) proportion of time alone, (C) proportion of associates that were male, (D) betweenness and 934 (E) Transitivity.

\begin{tabular}{|c|c|c|c|c|c|}
\hline & Model & DF & Loglik & ChiSq & $\mathbf{P}$ \\
\hline \multirow[t]{2}{*}{$\mathrm{A}$} & $\begin{array}{l}\text { Difference to median group size } \sim \text { ordered }(\text { Age })+ \\
\text { ordered }(\text { Colour })+(1 \mid \text { ID })+(1 \mid \text { Period })\end{array}$ & 12 & -77.95 & & \\
\hline & Null model & 3 & -98.22 & 40.55 & $<0.01 *$ \\
\hline \multirow[t]{2}{*}{$\mathrm{B}$} & $\begin{array}{l}\text { Difference to median proportion of time alone } \sim \\
\text { ordered(Age) }+ \text { ordered(Colour) }+(1 \mid \text { ID })+(1 \mid \text { Period })\end{array}$ & 12 & 1.43 & & \\
\hline & Null model & 3 & -7.46 & 17.78 & $0.04 *$ \\
\hline \multirow[t]{2}{*}{$\bar{C}$} & $\begin{array}{l}\text { Difference to median proportion of associates that were } \\
\text { male } \sim \text { ordered(Age) }+ \text { ordered(Colour) }+(1 \mid \text { ID })+ \\
(1 \mid \text { Period })\end{array}$ & 12 & 10.788 & & \\
\hline & Null model & 3 & 21.927 & 22.277 & $<0.01 *$ \\
\hline \multirow[t]{2}{*}{$\mathrm{D}$} & $\begin{array}{l}\text { Scaled betweenness rank } \sim \text { ordered(Age })+ \\
\text { ordered }(\text { Colour })+(1 \mid \text { ID })\end{array}$ & 11 & 4.59 & & \\
\hline & Null model & 3 & -5.94 & 21.06 & $<0.01 *$ \\
\hline \multirow[t]{2}{*}{$\bar{E}$} & $\begin{array}{l}\text { Scaled transitivity rank } \sim \text { ordered(Age })+ \text { ordered(Colour) } \\
+(1 \mid \text { ID })\end{array}$ & 11 & 6.91 & & \\
\hline & Null model & 3 & 2.31 & 9.181 & 0.33 \\
\hline
\end{tabular}




\section{Acknowledgements}

2 We would like to thank the Namibian Ministry of Environment and Tourism for allowing us to

3 conduct research in Namibia and Werner Kilian and the Etosha Ecological Institute for hosting us in

4 the Etosha National Park. We are grateful to the staff for sharing their knowledge, assisting with all

5 varieties of maintenance, sharing their coffee every morning and including us as part of their

6 community. Thank you to Thorsten Trede, Dietmar Prange, Matthias Lipps, Claudia Wolber-Lipps,

7 Peter Spaetling, Bernd Olejak and Alain Fontaine for allowing us the use of their giraffe photographs.

8 Thanks also to numerous volunteers who assisted with data collection, giraffe identification and

9 colour scoring, particularly Danie Brand, John Carter, Alan and Justin Goldizen, Molly Gilmore and

10 Aliesha Dodson. We must also acknowledge the many other researchers that became our friends

11 while living in the research camp. We thank Simon Blomberg for advice on statistical analysis and

12 two anonymous reviewers for constructive comments on the manuscript. This whole project was

13 inspired by L. M. Gosling to whom we are extremely grateful. Financial support was provided by the

14 National Geographic Society (2004-2005, 2013, 2015), Leiden Conservation Foundation (2016),

15 Wilderness Wildlife Trust (2009-2010) and Australian Geographic Society (2009-2010). We also

16 thank Tyres2000 Namibia and Heaney's Performers in Print who provided in-kind donations. MC and

$17 \mathrm{KC}$ were both supported by Australian Post Graduate Awards and postgraduate funding from the

18 University of Queensland. 


\section{$1 \quad$ Animal ethics note}

2

3 The data collection protocols used in this study were assessed and approved by the University of

4 Queensland Native/Exotic Wildlife and Marine Animals Animal Ethics Committee (approval

5 numbers SBS/439/14, SBS/093/11/GCF and SIB/124/09/URG). Data collection was approved by the

6 Namibian Ministry of Environment and Tourism under research permit numbers 2017/2016,

$72005 / 2015,1082 / 2013,1468 / 2010,1365 / 2009,876 / 2005$ and 760/2004. We followed all regulations

8 when working within Etosha National Park, including a maximum speed limit of $60 \mathrm{~km} / \mathrm{h}$ (we drove

9 much slower around wildlife $\sim 10 \mathrm{~km} / \mathrm{h}$ ) and remaining in a vehicle and on road when outside of the

10 rest camps.

11

12 This is was a purely observational study aiming to record natural behaviour of wild animals. Thus,

13 animals were not housed, translocated, fed, trapped or manipulated in any way. We identified

14 individuals by their unique spot patterns so no individual tagging was required. The national park is a

15 popular tourist attraction so the wildlife are habituated to observation from vehicles. We maintained a

16 respectful distance to not disturb natural behaviour and drove slowly around all wildlife.

17

18 Over our four data collection periods spanning twelve years we recorded data on 1484 individuals

19 (575 female, 668 male and 241 individuals of unknown sex). Data on 77 of these males was analysed

20 in this study. 